\title{
Editorial/Short Commentary/Expert Reviews on Topic of My Interest Relating To the Field of Health and Medical Informatics as an Initiative Yasuo Maeda* \\ Department of Developmental Biology and Neurosciences, Graduate School of Life Sciences, Tohoku University, Sendai, Japan
}

First of all, I think that J. Health and Medical Informatics (JHMI) is nicely named, because this journal must cover a wide range of information concerning health and medical sciences. In addition, I sincerely expect that this journal will have the function of linking aggressively information between purely basic scientific data and applied science fields.

To be quite honest, I am a beginner in the field of medical sciences, I had studied about transition mechanism of cells from growth to differentiation, using a nice developmental system of a model organism Dictyostelium, for a long time just before my retirement from Tohoku University. During a series of purely scientific works, we have found several genes and phosphoproteins that are specifically expressed or modified in the initiation of cell differentiation from GDT-point (growth/differentiation transition point) in the cell cycle. One of the most notable genes is Dd-mrp4 (Dictyostelium mitochondrial ribosomal protein $\mathrm{S} 4$ ): $D d-m r p 4$ gene expression is absolutely required for the initiation of cell differentiation and its null cells fail to initiate differentiation, while the initial step of cell differentiation and the subsequent morphogenesis are markedly enhanced in mrp4 ${ }^{\mathrm{OE}}$ cells overexpressing the $D d-m r p 4$ in the extra mitochondrial cytoplasm. This raised a possibility that the ectopically enforced expression of the $D d-m r p 4$ in human cells might inhibit their growth, particularly of malignant tumor cells, by inducing cell differentiation. Fortunately, we have demonstrated that ectopically enforced expression of the $D d$ mrp4 in human cells specifically suppress growth of several cancer cell lines examined, by means of induction apoptosis (programed cell death; ultimate cell differentiation). This incredibly amazing result has been recently published in "Cancer Cell International". This is a typical good example in which purely scientific data are directly connected to medical sciences including cancer therapy, suggesting strongly that the Dd-mrp4 gene derived from Dictyostelium (wide apart from human beings) mitochondria may provide a new promising therapeutic strategy for disrupting cell viability pathways in human cancers.

To improve the current situation, I strongly hope JHMI greatly contributes toward active and efficient communications between pure biological sciences and applied sciences as well as among all of health and medical sciences. For this, it will be needed that many scientists and students, irrespective of pure and applied sciences, submit their valuable experimental data or comments to JHMI and communicate well each other. I have just submitted a Mini-review entitled "A longrange foresight for the medical application of apoptosis specifically induced by Dd-MRP4, Dictyostelium mitochondrial ribosomal protein S4, to cancer therapy" to JHMI. I do not feel so much value in so called "Impact Factor" of each journal. Rather, it is more important for scientifically valued information to be conveyed correctly and quickly to a lot of people, because we are now in a well-established informative society, I believe.

Incidentally, my current interest is in the fields of cancer therapy, mitochondrial functions, apoptosis, cell and developmental biology, Dictyostelium, and human tumors.
*Corresponding author: Yasuo Maeda, Department of Developmental Biology and Neurosciences, Graduate School of Life Sciences, Tohoku University, Sendai, Japan, Tel: +81-22-224-2863; E-mail: kjygy352@ybb.ne.jp

Received October 13, 2014; Accepted October 15, 2014; Published October 20, 2014

Citation: Maeda Y (2014) Editorial/Short Commentary/Expert Reviews on Topic of My Interest Relating To the Field of Health and Medical Informatics as an Initiative. J Health Med Informat. 5: e133. doi:10.4172/2157-7420.1000e133

Copyright: ( 2014 Maeda Y. This is an open-access article distributed under the terms of the Creative Commons Attribution License, which permits unrestricted use, distribution, and reproduction in any medium, provided the original author and source are credited. 